\title{
Coronary artery bypass grafting bundled payment proposal will have significant financial impact on hospitals
}

\author{
Robert B. Hawkins, MD, MSc, ${ }^{a}$ J. Hunter Mehaffey, MD, MSc, ${ }^{a}$ Kenan W. Yount, MD, MBA, ${ }^{a}$ \\ Leora T. Yarboro, MD,${ }^{\mathrm{a}}$ Clifford Fonner, BA, ${ }^{\mathrm{b}}$ Irving L. Kron, MD, ${ }^{\mathrm{a}}$ Mohammed Quader, MD, \\ Alan Speir, MD, ${ }^{\mathrm{d}}$ Jeffrey Rich, MD, ${ }^{\mathrm{b}}$ and Gorav Ailawadi, MD, ${ }^{\mathrm{a}}$ Investigators for the Virginia Cardiac \\ Services Quality Initiative
}

\section{ABSTRACT}

Objectives: The Centers for Medicare and Medicaid Services plans to institute a 5-year trial of bundled payments for coronary artery bypass grafting through 90 days after discharge. To investigate the impact, we reviewed actual inpatient costs for patients undergoing bypass surgery relative to the target price.

Methods: A total of 13,276 Medicare patients with estimated cost data underwent isolated coronary artery bypass grafting from 2008 to 2015 in 18 hospitals over 8 Medicare-defined regions within the Commonwealth of Virginia. Actual 2015 inpatient costs were compared with estimated target prices for each year of the pilot, based on the previous 3 years and stratified by Diagnosis-Related Group.

Results: The mean 2015 cost per patient was \$50,394 with high variation (range, $\$ 27,862-\$ 74,169)$. On average, hospitals would receive a refund of $\$ 17,682$ in year 1, but then owe Medicare increasing amounts up to $\$ 367,985$ in year 5 . If 2015 were the final year of the pilot, 13 of the 18 hospitals $(72 \%)$ would have owed Medicare for cost overruns averaging \$614,270 (range, \$67,404$\$ 2,102,292)$. Costs were below the target price at 5 of 18 hospitals, and the Centers for Medicare and Medicaid Services would have paid them an extra \$272,355 on average (range, \$88,628-\$567,429).

Conclusions: Hospitals will face immediate financial pressure due to average cost increases of 3.6\% per year and an automatic reduction in payment. As regional pricing is phased in, hospitals can expect to owe Medicare increasing amounts. The net effect is shifting of financial risks to hospitals, which could restrict access to care for higher-risk patients. (J Thorac Cardiovasc Surg 2018;155:182-8)

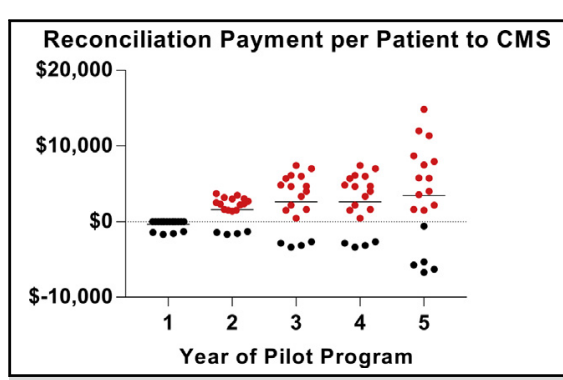

The mean CMS repayment per patient; positive red numbers indicate money owed to CMS.

\section{Central Message}

The bundled payment plan shifts financial risk to hospitals, possibly affecting access to care and hindering quality.

\section{Perspective}

The proposed bundled payment plan for isolated CABG will further shift financial responsibility to hospitals. The increased financial pressure has the potential to affect quality and access to care, making it paramount that administrators work with clinicians and researchers to ensure adequate risk adjustment, quality incentives, and guarantees for patient access.

See Editorial Commentary page 189.
The cost of health care in the United States of America has increased in an unsustainable manner for decades, is now a national burden at $\$ 3.2$ trillion per year, and is unaffordable for $53 \%$ of privately insured low-income individuals. ${ }^{1-4}$

From the ${ }^{\mathrm{a}}$ Division of Thoracic and Cardiovascular Surgery, University of Virginia, Charlottesville; ${ }^{\mathrm{b}}$ Virginia Cardiac Services Quality Initiative, Virginia Beach; ${ }^{\mathrm{c} D i}$ vision of Cardiothoracic Surgery, Virginia Commonwealth University, Richmond; and ${ }^{\mathrm{d} I N O V A}$ Heart and Vascular Institute, Falls Church, Va.

This work was supported in part by the National Institutes of Health (T32 HL07849).

Received for publication Jan 5, 2017; revisions received June 28, 2017; accepted for publication July 21, 2017; available ahead of print Sept 12, 2017.

Address for reprints: Gorav Ailawadi, MD, Division of Thoracic and Cardiovascular Surgery, University of Virginia, PO Box 800679, Charlottesville, VA 22908 (E-mail: GA3F@virginia.edu).

0022-5223/\$36.00

Copyright (c) 2017 by The American Association for Thoracic Surgery

http://dx.doi.org/10.1016/j.jtcvs.2017.07.035
The Virginia Cardiac Services Quality Initiative (VCSQI) has demonstrated that cardiac surgery has undergone similar cost increases, documented for both valve surgery and coronary artery bypass grafting (CABG) ${ }^{5,6} \mathrm{CABG}$ is a prime target for cost reduction because it represents the largest cost expenditure of any single procedure. ${ }^{7}$ Efforts to contain cardiac surgery costs began with the establishment of the Centers for Medicare and Medicaid Services

Scanning this QR code will take you to the article title page. 


\section{Abbreviations and Acronyms \\ CMS = Centers for Medicare and Medicaid Services \\ $\mathrm{CABG}=$ coronary artery bypass grafting \\ DRG = Diagnosis-Related Group \\ MSA = metropolitan statistical area \\ PROM = predicted risk of mortality \\ PROMM $=$ predicted risk of morbidity or mortality \\ STS = Society of Thoracic Surgeons \\ VCSQI = Virginia Cardiac Services Quality Initiative}

(CMS) Inpatient Prospective Payment System that bundled inpatient payments. ${ }^{8,9}$ Current efforts at payment reform began with passage of the Patient Protection and Accountable Care Act, which developed the Centers for Medicare and Medicaid Innovation under CMS in 2010. ${ }^{10}$ This has been accelerated with the recent passage of Medicare Access and CHIP Reauthorization Act of 2015 that addresses physician payments.

On July 25, 2016, the CMS issued a notice of a proposed rule for CABG bundled payments. ${ }^{11}$ Although not the first bundled payment program, this is one of the first to provide a fixed sum of money for comprehensive inpatient and outpatient care. The proposal is for a 5-year trial of bundled payments for isolated CABG from admission through 90 days after discharge in 98 metropolitan statistical areas (MSAs). Any Medicare patient undergoing CABG with a designation of Diagnosis-Related Group (DRG) 231-236 (Table 1) and not participating in a separate alternative payment program would be eligible for the bundled payment program. Hospitals will be paid under the standard fee-for-service arrangement with inpatient hospital costs reimbursed on the basis of the procedure, with the CMS making payments based on the DRG. At the end of each year, the CMS will reconcile all payments compared with a target price that is based on cost data from the prior 3 years. It phases in regional pricing and increasing caps for the reconciliation payment. The pilot program will split their calculations by phase of care and set target prices for the hospitalization and postdischarge care separately. To investigate the impact of the inpatient component of the proposal, we reviewed actual costs for patients undergoing $\mathrm{CABG}$ relative to the expected target price.

\section{MATERIALS AND METHODS \\ Patient Data}

The VCSQI is composed of 18 hospitals and cardiac surgical practices in Virginia that includes approximately $99 \%$ of adult cardiac surgery cases in the state. The hospitals are spread over 8 MSAs with a range of 1 to 5 hospitals per MSA. VCSQI clinical and cost data acquisition and matching have been described. ${ }^{5,12}$ Administrative, demographic, and clinical data are collected by each participating institution using the current Society of
Thoracic Surgeons (STS) clinical data entry form. The VCSQI database pairs STS data with hospital patient discharge information. Uniform Billing 04/92 files are matched to the STS data, with a successful matching rate of $99 \%$. These identify charges that are classified on the basis of International Classification of Diseases, Ninth Revision-based revenue codes. Cost-to-charge ratios submitted to the CMS by each institution are used to estimate costs. Cost data were adjusted to 2015 dollars using the market basket for the CMS Inpatient Prospective Payment System to account for medical specific inflation.

Records for isolated CABG $(\mathrm{n}=13,290)$ for patients insured by Medicare were identified for the period January 1, 2008, to December 31, 2015. Patients were excluded for missing cost data. Standard STS definitions were used, including operative mortality (in-hospital or 30-day mortality) and major morbidity (permanent stroke, prolonged ventilation, reoperation, renal failure, and deep sternal wound infection). This investigation was a secondary analysis of the VCSQI data registry without Health Insurance Portability and Accountability Act patient identifiers. Business associates agreements exist among VCSQI, member hospitals, and the database vendor (ARMUS Corporation, San Mateo, Calif). The study was granted exemption by the University of Virginia Institutional Review Board.

\section{Bundled Payment Modeling}

All hospitals were categorized by the MSA for analysis in a blinded manner. Historical pricing was calculated using inflation-adjusted total hospital costs from 2012 to 2014. Costs were stratified by DRG (Table 1) for riskadjustment purposes. A target price was then calculated for each of the 3 phases of the pilot program: Phase 1 is based on two thirds hospital cost and one third regional cost; phase 2 is one third hospital and two thirds regional cost; phase 3 is $100 \%$ regional costs (Table 2). An across the board 3\% reduction in the target price was incorporated; however, adjustment for high-quality hospitals could not be performed because of the lack of CMS quality data and cutoffs. This calculated target price was compared with actual costs for 2015. The reconciliation payment is the difference between the actual cost and the target price (actual 2015 costs - historical target price). As the pilot program progresses, there is an increasing cap on the reconciliation payment (Table 2). The first year precluded hospitals owing CMS reconciliation payments; however, this cap increased for years 2 to 5 and included both downside risk where hospitals owed CMS a reconciliation payment and upside risk where hospitals would receive money from CMS. Total hospital reconciliation payments were calculated using DRG-specific prices and volume. Hospitals were classified as penalized if they owed money to the CMS in the reconciliation payment for being over the target price, whereas hospitals that were paid by CMS for being under the target price were categorized as rewarded.

\section{Statistical Analysis}

Categoric data were summarized by proportions, and continuous data were summarized by median and interquartile range because of skewedness, except for cost data, which were presented as mean and standard deviation. Baseline characteristics and short-term outcomes were compared by MannWhitney $U$ test or chi-square test as appropriate. Multivariate generalized linear modeling was used to calculate inflation-adjusted total hospital cost as a function of MSA with nested models containing DRG and STS predicted risk of mortality (PROM) or morbidity or mortality (PROMM). All statistical analyses were performed using SAS version 9.4 (SAS Institute, Inc, Cary, $\mathrm{NC}$ ). The significance level of all tests was set at alpha $=0.05$.

\section{RESULTS}

The baseline characteristics and short-term outcomes for penalized and rewarded hospitals are displayed in Table 3. Patients cared for in penalized hospitals were statistically higher risk as measured by STS PROM (1.5\% $[0.9 \%-2.8 \%]$ vs $1.4 \%[0.9 \%-2.6 \%], P=.0005)$. This 
TABLE 1. Diagnosis-Related Group classifications

\begin{tabular}{lccc}
\hline CABG DRG & $\begin{array}{c}\text { Cardiac } \\
\text { catheterization }\end{array}$ & $\begin{array}{c}\text { Percutaneous } \\
\text { transluminal } \\
\text { coronary } \\
\text { angioplasty }\end{array}$ & $\begin{array}{c}\text { Major } \\
\text { complication or } \\
\text { comorbidity }\end{array}$ \\
\hline DRG 231 & Yes & Yes & Yes \\
DRG 232 & Yes & Yes & No \\
\hline DRG 233 & Yes & No & Yes \\
DRG 234 & Yes & No & No \\
\hline DRG 235 & No & No & Yes \\
DRG 236 & No & No & No \\
\hline
\end{tabular}

$C A B G$, Coronary artery bypass grafting; $D R G$, Diagnosis-Related Group.

trend translated into longer median crossclamp times at penalized hospitals (68 minutes [52-85] vs 60 minutes [45-76]). Considering that higher-risk patients were treated in penalized hospitals, the observed-to-expected ratio for operative mortality was calculated for both groups and was 0.87 for the penalized hospitals and 1.10 for the rewarded hospitals. The rate of major morbidity was significantly higher in penalized hospitals compared with rewarded ones $(13.8 \%$ vs $11.2 \%, P=.0002)$.

\section{Trends in Coronary Artery Bypass Grafting Cost}

CABG demonstrates 2 significant trends; the first is a steady increase in adjusted total hospital costs, and the other is significant variation by hospital. The mean hospital cost in 2015 dollars increased from $\$ 37,747$ in 2008 to $\$ 50,394$ in 2015 . There was also an increase in variability with the standard deviation increasing from $\$ 19,401$ to $\$ 26,897$ between 2008 and 2015 . This equates to an average yearly increase of $3.6 \%$. Despite these yearly increases, the proposal includes CMS reducing the target price by $3 \%$ (termed a discount), which compounds the financial pressure of the bundled payment system.

Total hospital cost from 2008 to 2015 varied widely across the state from a per patient average of $\$ 25,858$ to more than double that cost at $\$ 67,527$. This variation also is true within MSAs, where the range was nearly as large for the largest MSA as the entire state $(\$ 33,171-\$ 67,527)$. Finally, looking at only 2015 costs we continue to see large variation, with mean hospital costs demonstrated in Table 4 and ranging from $\$ 26,591$ to $\$ 74,169$. The mean cost for each MSA had less variation, but with a range of $\$ 25,858$ to $\$ 51,980$ is still an important consideration with the emphasis on regional pricing.

\section{Impact on Reimbursement}

The calculated reconciliation payment per patient (actual 2015 costs - historical target price) for each hospital is demonstrated in Figure 1 for each year of the pilot program and shown in detail in Table 4. Multiplying by the volume per DRG, Figure 2 demonstrates the total reconciliation payment for each hospital by year of the pilot program. The trend of increasing financial liability as the pilot program progresses is clear in Figures 1 and 2, driven by increasing caps. The average reconciliation payment to CMS in year 1 is $-\$ 17,683$ (additional reimbursement to hospital), compared with year 2: $\$ 166,418$; years 3 and 4: $\$ 276,055$; year 5: $\$ 367,985$ (all payments owed by hospitals to CMS). The average reconciliation payment for each phase of the pilot program was as follows: phase 1 (years 1 and 2): $\$ 74,368$; phase 2 (years 3 and 4): $\$ 276,055$; phase 3 (year 5): $\$ 367,985$. This equates to an average increase in the repayment owed to CMS of $\$ 146,809$ with each phase of the program.

In the final phase (year 5), 13 of the 18 hospitals (72\%) would have owed CMS reconciliation payments for cost overruns averaging \$614,270 (range, \$67,404$\$ 2,102,292)$. Costs were below the target price at only 5 of 18 hospitals, and the CMS would have paid back an average reconciliation of only $\$ 272,355$ (range, $\$ 88,628$ $\$ 567,429)$. Without the cap that is placed on these payments, the highest reconciliation payment owed to CMS would have remained at $\$ 2,102,292$, whereas the highest payment from CMS would have increased to $\$ 1,544,141$.

\section{Predictive Power of Current Model}

The pilot program is set to risk adjust by DRG, which accounts for cardiac catheterization, percutaneous coronary angioplasty, and major complication or comorbidity. However, linear regression shows that DRG accounts for only $24.5 \%$ of variation in inflation-adjusted total hospital cost after accounting for regional variation by MSA. STS PROM performs even worse, accounting for only $13.4 \%$

TABLE 2. Pilot program components by year and phase of implementation

\begin{tabular}{lllc}
\hline Phase & \multicolumn{1}{c}{ Year } & \multicolumn{1}{c}{ Pricing } & Repayment cap \\
\hline 1 & $1(10 / 17-12 / 17)$ & Two thirds hospital, one third regional ${ }^{*}$ & $0 \%$ downside, $5 \%$ upside $\dagger$ \\
1 & $2(2018)$ & Two thirds hospital, one third regional & $5 \%$ both \\
2 & $3(2019)$ & One third hospital, two thirds regional & $10 \%$ both \\
2 & $4(2020)$ & One third hospital, two thirds regional & $10 \%$ both \\
3 & $5(2021)$ & All regional & $20 \%$ both \\
\hline
\end{tabular}

*Regional defined as all hospitals within the MSA. †Downside risk indicates potential reconciliation payments owed to the CMS by the hospital, and upside risk indicates potential reconciliation payments owed to the hospital by CMS. 
TABLE 3. Baseline characteristics for Medicare cohort

\begin{tabular}{|c|c|c|c|}
\hline Baseline characteristics & Penalized $(n=10,060)$ & Rewarded $(\mathbf{n}=3230)$ & $P$ value \\
\hline Age [median, IQR] & $71[66-76]$ & $71[66-76]$ & .59 \\
\hline Female & $2969(29.5 \%)$ & $988(30.6 \%)$ & .24 \\
\hline Cerebrovascular disease & $1987(19.8 \%)$ & $720(22.4 \%)$ & .002 \\
\hline Hypertension & $9026(89.7 \%)$ & $2861(88.6 \%)$ & .06 \\
\hline 3-vessel coronary disease & $7906(78.7 \%)$ & $2432(75.3 \%)$ & $<.0001$ \\
\hline Prior myocardial infarction & $4933(49.1 \%)$ & $1640(50.8 \%)$ & .09 \\
\hline Diabetes & $4626(46.0 \%)$ & $1491(46.2 \%)$ & .86 \\
\hline Prior cardiac surgery & $364(3.6 \%)$ & $108(3.3 \%)$ & .46 \\
\hline PROM [median, IQR] & $1.5 \%[0.9 \%-2.8 \%]$ & $1.4 \%[0.9 \%-2.6 \%]$ & .0005 \\
\hline \multicolumn{4}{|l|}{ Short-term outcomes } \\
\hline Operative mortality & $225(2.2 \%)$ & $83(2.6 \%)$ & .27 \\
\hline Operative mortality O:E & 0.87 & 1.10 & \\
\hline Major morbidity & $1389(13.8 \%)$ & $362(11.2 \%)$ & .0002 \\
\hline Postoperative LOS [d; median, IQR] & $6[5-8]$ & $5[4-7]$ & $<.0001$ \\
\hline Discharge to a facility & $2643(26.8 \%)$ & $825(26.0 \%)$ & .38 \\
\hline Readmission & $966(9.9 \%)$ & $345(11.0 \%)$ & .08 \\
\hline
\end{tabular}

$I Q R$, Interquartile range; PROM, predicted risk of mortality; $O: E$, observed to expected ratio; $L O S$, length of stay.

of cost variation. STS PROMM is a bit better with the $\mathrm{R}^{2}$ for the model of $18.5 \%$. However, there is substantial covariance between DRG and PROMM, where linear regression combining DRG and STS PROMM accounts for only $28.4 \%$ of variation.

\section{DISCUSSION}

There is significant variation in Medicare patient costs for CABG within the Commonwealth of Virginia and within individual MSAs. This variation in combination with the high cost of the surgery represents a potentially large source of

TABLE 4. Statewide financial impact modeling the final year of the pilot

\begin{tabular}{|c|c|c|c|c|c|}
\hline Hospital & MSA & Actual cost & Uncapped repayment per person & Capped repayment per person & Capped total repayment \\
\hline A & 1 & $\$ 46,183$ & $\$(624)$ & $\$(624)$ & $\$(88,628)^{*}$ \\
\hline B & 1 & $\$ 59,931$ & $\$ 17,603$ & $\$ 11,986$ & $\$ 1,018,830$ \\
\hline $\mathrm{C}$ & 2 & $\$ 69,883$ & $\$ 8690$ & $\$ 8690$ & $\$ 504,020$ \\
\hline $\mathrm{D}$ & 2 & $\$ 74,169$ & $\$ 27,304$ & $\$ 14,834$ & $\$ 949,360$ \\
\hline $\mathrm{E}$ & 2 & $\$ 31,524$ & $\$(17,157)$ & $\$(6305)$ & $\$(567,429)$ \\
\hline $\mathrm{F}$ & 2 & $\$ 28,731$ & $\$(18,199)$ & $\$(5746)$ & $\$(206,860)$ \\
\hline G & 2 & $\$ 60,880$ & $\$ 11,350$ & $\$ 11,350$ & $\$ 1,044,229$ \\
\hline $\mathrm{H}$ & 3 & $\$ 46,354$ & $\$ 5771$ & $\$ 5771$ & $\$ 138,513$ \\
\hline I & 3 & $\$ 53,564$ & $\$ 3548$ & $\$ 3548$ & $\$ 67,404$ \\
\hline $\mathrm{J}$ & 3 & $\$ 46,789$ & $\$ 5747$ & $\$ 5747$ & $\$ 856,262$ \\
\hline K & 4 & $\$ 63,607$ & $\$ 7488$ & $\$ 7488$ & $\$ 262,088$ \\
\hline $\mathrm{L}$ & 4 & $\$ 33,684$ & $\$(15,779)$ & $\$(6737)$ & $\$(222,314)$ \\
\hline M & 4 & $\$ 26,591$ & $\$(21,557)$ & $\$(5318)$ & $\$(276,545)$ \\
\hline $\mathrm{N}$ & 4 & $\$ 63,328$ & $\$ 7933$ & $\$ 7933$ & $\$ 2,102,293$ \\
\hline $\mathrm{O}$ & 5 & $\$ 27,347$ & $\$ 2171$ & $\$ 2171$ & $\$ 138,964$ \\
\hline $\mathrm{P}$ & 6 & $\$ 39,641$ & $\$ 1494$ & $\$ 1494$ & $\$ 144,965$ \\
\hline Q & 7 & $\$ 46,270$ & $\$ 1606$ & $\$ 1606$ & $\$ 134,895$ \\
\hline $\mathrm{R}$ & 8 & $\$ 50,309$ & $\$ 4024$ & $\$ 4024$ & $\$ 623,693$ \\
\hline
\end{tabular}

MSA, Metropolitan statistical area. *Parentheses indicate negative reconciliation payments (CMS owes money back to the hospital) 


\section{Reconciliation Payment per Patient to CMS}

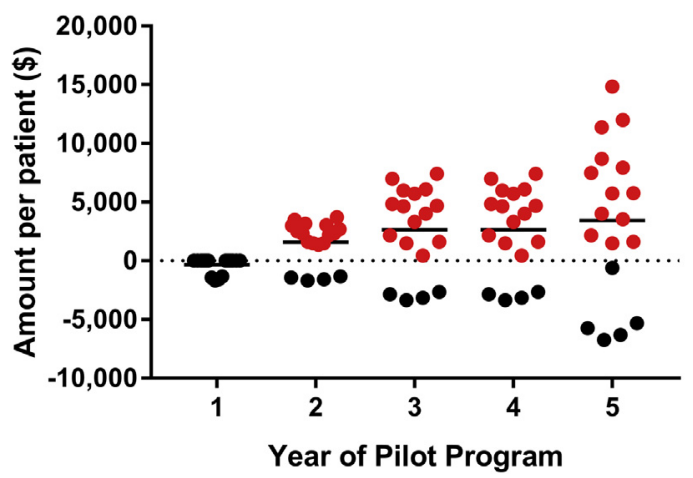

FIGURE 1. The mean CMS repayment per patient by hospital if 2015 had been each of the 5 years of the pilot. Positive red numbers indicate money owed by the hospital to CMS for being above the target price. CMS, Centers for Medicare and Medicaid Services.

savings for CMS. However, it also creates the potential for fiscal risk that hospitals may not be able to absorb. ${ }^{13}$ This places cardiac practices at risk, but more importantly places patient access to care in jeopardy. The $72 \%$ of hospitals that are going to owe reconciliation payments to CMS at the end of the year are going to look for cost savings measures going forward. This will hopefully include quality improvement, care coordination, and other measures to improve patient care. However, the financial risk could lead to an aversion by hospitals and practices to accept patients at risk for high costs.

Multiple investigations of the large variation in inpatient costs for CABG have demonstrated hospital-specific variation independent of patient factors. ${ }^{13,14}$ Although there is a dearth of data regarding what exactly the hospital-specific factors are and how great the potential for savings are with standardization of care, these health care systembased opportunities are the focus of the CMS payment

\section{Total Reconcilation Payment to CMS}

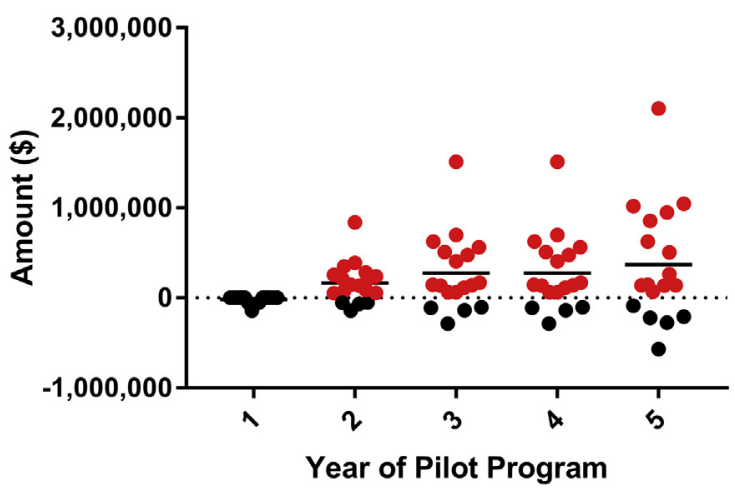

FIGURE 2. The total reconciliation payment for each hospital calculated for 2015 costs as each year of the pilot program. CMS, Centers for Medicare and Medicaid Services. reform models. The shift to regional pricing should help to force collaboration and standardization. However, the bundled payment model that has been proposed is also designed to extract overall savings. The 3\% reduction that the CMS is applying to lower the target price compounds the $3.6 \%$ average CABG cost increases seen year over year in this analysis. Although postdischarge data are not currently available, a similar trend is likely to exist with previous estimates demonstrating an $8.3 \%$ increase per year. ${ }^{8}$ Although the adjustment for high-quality, high-value centers helps slightly mitigate this impact, the overall design is a decrease in reimbursement. The capping of repayments also benefits CMS disproportionately where the largest payment owed to CMS $(\$ 2,102,292)$ was not capped, but the largest payment CMS owes to a hospital was capped $(\$ 567,429)$ and much lower than the potential payment of $\$ 1,544,141$.

The current model relies heavily on DRG to risk adjust the target prices. However, this only accounts for limited factors including cardiac catheterization, angioplasty, and presence of major complications or comorbidity. The addition of clinical factors, even as an aggregate such as STS PROM or PROMM, improves the predictive power of the model. However, it still accounts for only $28.4 \%$ of cost variation. The limitations of PROM to risk adjust bundled payments have been well described. ${ }^{13}$ In a high-volume center with a high-risk population using the proposed methodology, the $75.5 \%$ of unexplained cost variation represents a potentially large financial risk. One institution would have owed CMS more than $\$ 2$ million $(12.5 \%$ of their total cost) if 2015 had been the final year of the pilot program.

These results have the potential to reshape hospital policy and limit access to care for vulnerable populations. The shifting of financial responsibility to hospitals places them at the center of decisions regarding patient care. This is contrary to the movement to have patient-centered decisions. The best interests of the patient are put further in jeopardy by 2 findings regarding risk and quality. First, hospitals that would be penalized under the proposed program performed $\mathrm{CABG}$ on statistically higher-risk patients. Second, these same hospitals had a lower observed to expected mortality rate than hospitals that would be rewarded under the pilot program. These findings corroborate prior research demonstrating a lack of correlation between quality and cost. ${ }^{15}$ These results suggest that the current risk stratification methodology using DRG is inadequate and highquality centers may be disproportionately penalized.

Models that incorporate adverse events vastly outperform those that contain only preoperative patient characteristics. ${ }^{15}$ This is not surprising considering the additive costs of postoperative complications. ${ }^{16,17}$ The costs of complications may range from a low of $\$ 9000$ for atrial fibrillation up to $\$ 63,000$ for mediastinitis. ${ }^{16,18}$ The STS 
PROMM outperforms PROM because it better incorporates some of the factors that increase risk for these expensive complications. The development of a cost model that performs well will require careful consideration of potential risks for complications. Because PROM uses fixed parameter estimates derived to predict risk of mortality, these are likely not optimized to predict costs, and a new model derived using CMS financial data has the potential to dramatically improve predictive power. It is imperative that administrators work with physicians and researchers to use a combination of clinical, socioeconomic, administrative, and financial data to develop the best possible payment models.

The history of bundled payments for cardiac surgery is one of incremental expansion extending back to the establishment of the DRG payment structure, which bundled inpatient care. ${ }^{9}$ Although this helped slow the increase in Medicare payments, it was taken further in 1991 with the creation of the Medicare Participating Heart Bypass Center Demonstration with bundling of inpatient, physician, and readmission costs. ${ }^{8}$ By the end of the project in 1996, 7 hospitals had participated and showed a $10 \%$ decrease in costs over 5 years. Only $5 \%$ of the decrease in costs was associated with postdischarge care expenses. The noneconomic impacts, such as on outcomes and quality of care, were less clear, but there was a small increase in complications. More recently, the Geisinger Health Plan implemented a comprehensive bundled payment system that covered preoperative, inpatient, physician, postacute care, and readmissions. ${ }^{19}$ They also paired pay-for-performance with 40 best practices. They found modest cost and resource improvements, but compliance with the best practices increased from $40 \%$ to $100 \%$. Although lessons certainly can be learned from their experience, their uniquely integrated hospital and insurance structure within a specific region may limit translation of their model on a national scale.

The current proposal is based on previous work by the Centers for Medicare and Medicaid Innovation, which was established by the Affordable Care Act. However, it seems to lack some of the lessons learned from previous bundled payment efforts in cardiac care. ${ }^{20}$ A clear focus has been cost savings, but these have been modest in past programs. Achieving such savings through a 3\% discount risks jeopardizing quality and access. The $1.5 \%$ adjustment for high-quality hospitals may not be sufficient to prevent such consequences without increasing stop-loss protection for high cost cases, risk corridors to allow hospitals time to adapt, or risk pooling among many hospitals. Risk adjustment beyond DRG and transfer status could further help alleviate these concerns, but could still prove inadequate. ${ }^{13}$ Furthermore, such efforts require greater coordination between CMS administrators and clinical researchers than has been currently demonstrated. The relative success of the Geisinger plan may be related to their integrated structure but also to the alignment of incentives with payfor-performance and clear guidelines. The implementation of best practices to improve quality of care addresses both quality and cost, because the majority of cost variation appears to be the result of postoperative complications. ${ }^{14-16}$

\section{Study Limitations}

This analysis has several limitations related to data availability. Namely, this analysis only uses hospital-related costs as physician reimbursement, and postacute care costs were not available. However, we would expect some collinearity of the costs to mitigate this impact, which is supported by the modest decrease in postacute care cost seen with the Medicare Participating Heart Bypass Center Demonstration. ${ }^{8,9}$ Further limiting this impact, the CMS has estimated that the initial hospitalization will account for $75 \%$ of costs. ${ }^{10}$ In addition, the limited information in the proposal precludes adjusting the discount by the quality of hospital care. Finally, transfer status is expected to be incorporated in the pilot program, but is not tracked in detail in our dataset. These limitations highlight the need for improved access to Medicare financial data and increased coordination between CMS and regional collaboratives to improve future payment models. Access to these data also is critical for hospitals to increase care coordination and identify methods for cost containment. Finally, the political uncertainty with a new CMS administration may affect whether bundled payment systems are implemented. Nevertheless, increasing financial pressures and the growing number of private sector bundled payment schemes inevitably highlight the relevance of this analysis. This financial liability will likely motivate hospitals to contain costs that will limit downside risk, and thus these numbers likely overestimate the impact in the later years of the pilot program.

\section{CONCLUSIONS}

Cardiac surgery has been a target for bundled payments for decades with incremental expansion culminating in the current bundled payment proposal for isolated CABG. The proposal can be expected to shift financial risk and place the burden of postacute care coordination on hospitals. As a result, most hospitals can expect to owe CMS reconciliation payments at the end of the year that increase as regional pricing is phased into the model. Protections for quality and access to care are not built into the proposal, but improved risk-models and pay-for-performance with bestpractice implementation have shown previous promise. Additional considerations for risk pooling, risk corridors, and stop-loss protection could further help bundled payments to be financially viable. The current health care policy climate is shifting rapidly, but bundled payments are likely to persist. Cardiac surgeons and clinical researchers should be ready to help improve such systems with the goal of improving patient care. 


\section{Conflict of Interest Statement}

A.S. is a consultant on the Medtronic Cardiac Surgery Advisory Board. G.A. is a consultant for Abbott, Edwards, and Medtronic, and a speaker for AtriCure in the last 3 years but not within the last year. All other authors have nothing to disclose with regard to commercial support.

\section{References}

1. Collins SR, Gunja MZ, Doty MM, Beutel S. How high is America's health care cost burden? Findings from the Commonwealth Fund Health Care Affordability Tracking Survey, July-August 2015. Issue Brief (Commonw Fund). 2015;32:1-15.

2. Martin AB, Hartman M, Benson J, Catlin A, Accounts NHE. National health spending in 2014: faster growth driven by coverage expansion and prescription drug spending. Health Aff (Millwood). 2016;35:150-60.

3. Thorpe KE. The rise in health care spending and what to do about it. Health Aff (Millwood). 2005:24:1436-45.

4. Historical Health Care Expenditures. Centers for Medicare and Medicaid Services. 2016. Available at: https://www.cms.gov/research-statistics-data-andsystems/statistics-trends-and-reports/nationalhealthexpenddata/nationalhealthaccountshistorical.html. Accessed December 11, 2016.

5. Osnabrugge RL, Speir AM, Head SJ, Fonner CE, Fonner E Jr, Ailawadi G, et al. Costs for surgical aortic valve replacement according to preoperative risk categories. Ann Thorac Surg. 2013;96:500-6.

6. Yount KW, Rich JB, Lau CL, Ghanta RK, Yarboro LT, Kern JA, et al. The costs of our traditional yardsticks for quality: is value improving in cardiac surgery? Presented at: 42nd Annual Meeting of the Western Thoracic Surgical Association; June 22-25, 2016; Waikoloa, Hawaii.

7. Epstein AJ, Polsky D, Yang F, Yang L, Groeneveld PW. Coronary revascularization trends in the United States, 2001-2008. JAMA. 2011;305:1769-76.

8. Cromwell J, Dayhoff DA, Thoumaian AH. Cost savings and physician responses to global bundled payments for Medicare heart bypass surgery. Health Care Financ Rev. 1997; 19:41-57.

9. Shih T, Chen LM, Nallamothu BK. Will bundled payments change health care? Examining the evidence thus far in cardiovascular care. Circulation. 2015;131:2151-8.

10. Bundled Payments for Care Improvement (BPCI) Initiative: General information. Centers for Medicare \& Medicaid Services. 2016. Available at: http://innovation.cms.gov/initiatives/bundled-payments. Accessed December 13, 2016.

11. Notice of proposed rulemaking for bundled payment models for high-quality, coordinated cardiac and hip fracture care. Centers for Medicare \& Medicaid Services. 2016. Available at: https://www.cms.gov/Newsroom/MediaRelease Database/Fact-sheets/2016-Fact-sheets- items/2016-07-25.html. Accessed December $13,2016$.

12. Ailawadi G, LaPar DJ, Speir AM, Ghanta RK, Yarboro LT, Crosby IK, et al. Contemporary costs associated with transcatheter aortic valve replacement: a propensity-matched cost analysis. Ann Thorac Surg. 2016;101:154-60.

13. Yount KW, Isbell JM, Lichtendahl C, Dietch Z, Ailawadi G, Kron IL, et al. Bundled payments in cardiac surgery: is risk adjustment sufficient to make it feasible? Ann Thorac Surg. 2015;100:1646-52.

14. Kilic A, Shah AS, Conte JV, Mandal K, Baumgartner WA, Cameron DE, et al. Understanding variability in hospital-specific costs of coronary artery bypass grafting represents an opportunity for standardizing care and improving resource use. J Thorac Cardiovasc Surg. 2014;147:109-15.

15. Osnabrugge RL, Speir AM, Head SJ, Jones PG, Ailawadi G, Fonner CE, et al. Prediction of costs and length of stay in coronary artery bypass grafting. Ann Thorac Surg. 2014;98:1286-93.

16. Speir AM, Kasirajan V, Barnett SD, Fonner E Jr. Additive costs of postoperative complications for isolated coronary artery bypass grafting patients in Virginia. Ann Thorac Surg. 2009;88:40-6.

17. Rich JB, Speir AM, Fonner E Jr. Virginia Cardiac Surgery Quality Initiative. Making a business case for quality by regional information sharing involving cardiothoracic surgery. Am Heart Hosp J. 2006;4:142-7.

18. LaPar DJ, Speir AM, Crosby IK, Fonner E Jr, Brown M, Rich JB, et al. Postoperative atrial fibrillation significantly increases mortality, hospital readmission, and hospital costs. Ann Thorac Surg. 2014;98:527-33.

19. Casale AS, Paulus RA, Selna MJ, Doll MC, Bothe AE Jr, McKinley KE, et al. "ProvenCareSM": a provider-driven pay-for-performance program for acute episodic cardiac surgical care. Ann Surg. 2007;246:613-23.

20. Mechanic R, Tompkins C. Lessons learned preparing for Medicare bundled payments. N Engl J Med. 2012;367:1873-5.

Key Words: health care economics, bundled payments, alternative payment models, CABG 